\title{
UM POSICIONAMENTO JURÍDICO-FILOSÓFICO CONTRA A METAFÍSICA DOS "ISMOS": UMA ANÁLISE SOBRE OS ANIMAIS
}

\section{Emilien Vilas Boas Reis}

Pós-doutor em filosofia pela Universidade do Porto (2014), doutor em filosofia pela Pontifícia Universidade Católica do Rio Grande do Sul (2010), mestre em Filosofia pela Pontificia Universidade Católica do Rio Grande do Sul (2006) e graduação em Filosofia pela Universidade Federal de Minas Gerais (2004). É professor Adjunto da Escola Superior de Ensino Dom Helder Câmara (BH) em nível de graduação e pós-graduação (Mestrado). Email: mboasr@yahoo.com.br

\section{Bruno Torquato de Oliveira Naves}

Doutor e Mestre em Direito pela PUC Minas; Professor do Mestrado em Direito Ambiental e Desenvolvimento Sustentável da Escola Superior Dom Helder Câmara, Belo Horizonte-MG (Brasil); Coordenador do Curso de Especialização em Direito Urbanístico e Ambiental da PUC Minas Virtual, Belo Horizonte-MG (Brasil); Professor nos Cursos de Graduação e Especialização em Direito da PUC Minas e da Escola Superior Dom Helder Câmara, Belo Horizonte-MG (Brasil); Pesquisador do CEBID - Centro de Estudos em Biodireito (cebid.com.br). Email: brunotorquato@hotmail.com

\section{Luiz Gustavo Gonçalves Ribeiro}

Pós-doutor pela Universitá degli Studi di Messina/Itália. Doutor e Mestre em Ciências criminais pela Universidade Federal de Minas Gerais (UFMG). Professor de Graduação e Pós-graduação da Escola Superior Dom Helder Câmara (ESDHC). Promotor de Justiça do Ministério Público do Estado de Minas Gerais. Email: gustian@terra.com

\section{RESUMO}

Inicialmente, o texto propõe uma retomada histórica da relação entre seres humanos e demais animais, desde sua origem pré-histórica até a domesticação. Depois, a partir de Heidegger, faz uma crítica a posições metafísicas que pretendam fundamentar a relação humana com os outros animais, por serem arbitrárias. Também critica a retomada de autores clássicos para justificarem determinada relação com animais, utilizando Kant como exemplo, por ser insuficiente. Por fim, o texto se preocupa com a construção de políticas públicas que consagrem a saúde animal e a tutela da vida de todos os seres. Uma vez que a saúde única não é adotada no Brasil e que, no âmbito penal, a vida do animal doméstico não é sequer tutelada, a proposta é de que os animais sejam tratados pelo simples fato de serem. A pesquisa é de cunho teórico-bibliográfico e apresenta raciocínio dedutivo. 
Palavras-chave: Animais; Pré-história; Domesticação; Saúde Única; Vida; Heidegger; Bioética.

\author{
A LEGAL-PHILOSOPHICAL POSITIONING AGAINST THE \\ METAPHYSICS OF THE "ISMS": AN ANALYSIS ON ANIMALS
}

ABSTRACT

Initially, this paper proposes a historical resumption of the relationship between humans and other animals, from its prehistoric origin to domestication. Then, from Heidegger, the text criticizes metaphysical positions that intend to ground the human relationship with other animals, because they are arbitrary. It also criticizes the resumption of classical authors to justify a certain relationship with animals, using Kant as an example, because it is insufficient. Finally, the text is concerned with the construction of public policies that consecrate animal health and the protection of the life of all beings. Since single health is not adopted in Brazil and in the criminal sphere the life of the domestic animal is not even protected, the proposal is that the animals be treated for the simple fact of being. The research is theoretical-bibliographic and presents deductive reasoning.

Keywords: Animals; Prehistory; Domestication; Health; Heidegger; Bioethics. 


\section{INTRODUÇÃO}

A origem e a evolução das espécies, a seleção natural, a alimentação e a domesticação foram marcos históricos da aproximação entre os homens e os animais, o que hoje é objeto de estudos que identificam o surgimento dessa relação por razões de sobrevivência e o desenvolvimento dela em razão da domesticação animal pelo ser humano.

Os hábitos alimentares e o metabolismo proporcionaram uma identidade física e craniana que diferenciou os seres, e a domesticação, em três etapas evolutivas, marcou a convivência entre todos.

Hoje, contudo, essa relação ganha contornos teóricos, ora estudados sob a ótica antropocentrista, ora sob o aspecto biocêntrico ou ecocêntrico, de forma a colocar em evidência o homem ou os próprios seres em geral.

Todavia, tratar a relação homem-animal de tal ou qual forma antropocêntrica ou biocêntrica e ecocêntrica revela a eventualidade ou efemeridade da própria relação, posto que susceptível a interpretações arbitrárias, sujeitas aos acasos das conveniências e sem uma reflexão adequada.

Por conta disso, o texto que ora se apresenta propõe uma crítica filosófica que tem em Heidegger um referencial que leva à reflexão da arbitrariedade metafísica tradicional, questionando os pressupostos essencialistas dos entes, dos homens e do mundo, ainda camuflado nas diferentes áreas do saber, incluindo o Direito. O homem, enquanto formador de mundo, por isso, projeto, tem a capacidade de aperfeiçoar a relação com os demais animais, que não está condicionada aos problemas atuais.

A análise também abarca a Bioética, e teve na obra de Hans Jonas (2004) outro importante referencial teórico, de molde a ilustrar o equívoco do estudo das relações entre o homem e o animal que retomam os teóricos da tradição, adaptando-os aos novos tempos, como, por exemplo, em relação ao imperativo categórico kantiano. A proposta é de um outro imperativo categórico que, no contexto de uma nova Bioética, rompe com o paradigma individualista e se propaga para o público, para a sociedade presente e futura, inclusive para os demais seres e ecossistemas.

Tomando por base essa proposta filosófica e da nova Bioética, o texto recomenda uma visão de políticas públicas que acolham os seres humano e animal por sua dignidade própria, razão de ser de política de saúde única e de leis penais mais adequadas, que tutelem a vida animal, assim como a humana, enquanto tal, o que, todavia, não tem sido visto e pratica- 
do, mormente no tocante à tutela da vida do animal doméstico.

Há, portanto, um tema-problema que diz respeito à razão de ser de políticas públicas que consagrem a saúde única em prol de todos os seres e a tutela penal da vida animal. A hipótese, fulcrada em Heidegger e Jonas, é a de que os animais são merecedores dessas construções jurídicas em razão de serem, sem que sobre isso recaiam rótulos extraídos da metafísica.

No capítulo inaugural será tratada a relação homem-animal desde a pré-história, assunto que terá seguimento com a reflexão filosófica desenvolvida a partir de Heidegger.

O capítulo seguinte cuidará de desenvolver o novo imperativo categórico proposto por Hans Jonas que se apresenta como referencial mais adequado para o trato das relações entre homem e animal por não desenvolver, em essência, construções sedimentadas pela racionalidade antropocêntrica, em que considerada a individualidade humana, mas sim a solidariedade entre os seres em geral.

O capítulo final discorre sobre a saúde única como política pública mais adequada para a tutela dos seres, ante aos referenciais teóricos anteriormente estudados, o que também justifica a crítica à ausência de lei penal que consagre a vida do animal doméstico no Brasil.

A pesquisa é, portanto, interdisciplinar, de cunho teórico-bibliográfico, e emprega o raciocínio dedutivo de que a solidariedade entre os seres é razão para o estabelecimento de práticas jurídicas que venham consagrar a tutela dos demais animais.

\section{REFLEXÃO FILOSÓFICA SOBRE A RELAÇÃO DO SER HU- MANO COM OS DEMAIS ANIMAIS}

O trato da relação entre os homens e os animais remonta à própria pré-história, motivo pelo qual conveniente é a realização da contextualização histórica dessa aproximação para que as reflexões filosóficas sobre o tema sejam encetadas e desenvolvidas. É o que passará a ser feito doravante.

\subsection{Análise histórica}

A relação entre os seres humanos e os animais tem uma longa trajetória. Para caracterizá-la, é interessante voltar às origens, relatando a 
própria evolução da espécie humana. Há tempos, biólogos e antropólogos têm se debruçado sobre os aspectos que possibilitaram o surgimento da espécie humana. Inúmeras teorias foram levantadas. Entretanto, nos últimos anos, consolidou a hipótese de que a seleção natural atuou neste processo.

Um dos elementos fundamentais para a seleção natural é a alimentação. Tem-se defendido a ideia de que os nutrientes alimentares e a energia acumulada foram fundamentais para as mudanças fisiológicas das espécies.

Um estudo (LEONARD; ROBERTSON, 1994) comparou espécies diferentes de primatas com homens, chegando à constatação de que os tamanhos dos corpos estão relacionados aos tipos de nutrientes alimentares ingeridos. Gorilas e Orangotangos possuem corpos grandes, pois comem alimentos difíceis de serem ingeridos e com baixo nível de nutrientes, como folhas e cascas. Por outro lado, pequenos primatas ingerem insetos e seiva, alimentos mais fáceis de serem comidos e com maior nível de nutrientes. Caçadores-coletores modernos, que representariam a condição primitiva do Homo sapiens, por sua vez, se alimentam de uma dieta com alto nível calórico, devido às suas necessidades metabólicas. (LEONARD; ROBERTSON, 1994, p. 78-81).

Outra hipótese levantada para diferentes dietas energéticas entre as espécies é o tamanho do cérebro. Estudos com 31 espécies de primatas mostram que os seres humanos consomem de três a quatro vezes mais metabolismo cerebral do que os demais primatas, o que significa que a evolução dos hominídeos dependeu, dentre outros fatores, da quantidade de energia metabólica no cérebro, que o fez aumentar de tamanho:

\footnotetext{
Estes resultados implicam que mudanças na qualidade da dieta durante a evolução dos hominídeos estão relacionadas à evolução do tamanho do cérebro. A mudança para uma dieta mais caloricamente densa provavelmente foi necessária para aumentar substancialmente a quantidade de energia metabólica usada pelo cérebro dos hominídeos. Assim, enquanto os fatores nutricionais por si só não são suficientes para explicar a evolução dos cérebros grandes, parece claro que certas mudanças na dieta foram necessárias para que uma evolução substancial do cérebro ocorresse. ${ }^{1}$ (LEONARD; ROBERTSON, 1994, p. 83).

1 Tradução de: "These results imply that changes in diet quality during hominid evolution were linked with the evolution of brain size. The shift to a more calorically dense diet was probably needed in order to substantially increase the amount of metabolic energy being used by the hominid brain. Thus, while nutritional factors alone are not sufficient to explain the evolution of our large brains, it seems clear that certain dietary changes were necessary for substantial brain evolution to take place".
} 
Das análises coletadas pode-se depreender que as necessidades alimentares humanas dependeram do metabolismo do cérebro humano, maior do que os dos demais primatas. A questão que se coloca é em que momento no processo evolutivo ocorreram as mudanças alimentares e metabólicas que proporcionaram o aumento do cérebro. Mesmo que a resposta gire em torno de hipóteses, a análise dos fósseis de hominídeos oferece alguns indícios. Os tamanhos do cérebro e do corpo dos espécimes primatas podem ser usados como comparativo entre eles, avaliando a relação entre o tamanho do cérebro e sua taxa metabólica. (LEONARD; ROBERTSON, 1994, p. 83).

Leonard e Robertson (1994) fazem uma comparação entre seis espécies de hominídeos fosseis, levando em conta a capacidade craniana, o peso corporal estimado e a taxa metabólica de repouso, que significa o gasto de energia corporal para manter, em repouso, o funcionamento do corpo. Ao comparar os Homo habilis e o Homo erectus, primeiras espécies do gênero Homo, com os Australopithecus, percebe-se que os cérebros das espécies do gênero Homo são maiores que a espécie anterior, Australopithecus, o que coincide com o fato das espécies Homo terem aprendido a coletar e compartilhar recursos, o que gerou uma mudança alimentar, incluindo um maior consumo de dieta animal.

Especificamente, as evidências arqueológicas e morfológicas indicam que esses primeiros membros do gênero Homo incorporaram maiores quantidades de material animal em sua dieta do que os australopitecinos (Bunn, 1981; Wolpoff, 1980). Com o Homo inicial, há a primeira evidência clara de bases domésticas, implicando que os recursos foram coletados e trazidos de volta para um local central onde foram compartilhados (Potts, 1988). Portanto, é provável que o que apoiou a rápida expansão do tamanho do cérebro no Homo habilis e no Homo erectus fosse tanto a maior qualidade quanto a maior estabilidade da dieta. ${ }^{2}$ (LEONARD; ROBERTSON, 1994, p. 83-84).

Em comparação com outros primatas, o ser humano consome mais carne. $30 \%$ em média de sua base energética advém de alimentos com base animal, já chimpanzés consomem entre 5 e 7\%: "A adaptação a essa

2 Tradução de: "Specifically, both the archeological and morphological evidence indicate that these early members of the genus Homo incorporated greater amounts of animal material in their diet than the australopithecines (Bunn, 1981; Wolpoff, 1980). With early Homo there is the first clear evidence of home bases, implying that resources were collected and brought back to a central location where they were shared (Potts, 1988). Hence, it is likely that what supported the rapid expansion of brain size in Homo habilis and Homo erectus were both the higher quality and greater stability of the diet". 
dieta caloricamente densa e fácil de digerir é evidente em nossa morfologia intestinal, já que os seres humanos têm um trato digestivo relativamente reduzido em comparação com a maioria dos outros primatas"3. (Sussman, 1987; Chivers and Hladik, 1980; Milton, 1987)". (LEONARD; ROBERTSON, 1994, p. 85).

De acordo com Leonard e Robertson (1994), em média, os primatas gastam de 8 a 9\% de sua taxa metabólica de repouso com o cérebro. As espécies que gastam proporcionalmente mais dessa taxa em seu cérebro, possuem uma dieta alimentar de melhor qualidade. Por sua vez, cérebros pequenos necessitam de dietas alimentares de baixa qualidade. Sobre os seres humanos é possível afirmar que: "Os seres humanos representam o extremo positivo, tendo uma dieta de alta qualidade e um cérebro responsável por 20 a $25 \%$ da energia metabólica em repouso"4 (LEONARD; ROBERTSON, 1994, p. 85). Assim, pode-se afirmar uma possível relação entre a taxa metabólica de repouso e o tamanho do cérebro.

Registros fósseis indicam que para o surgimento do gênero Homo, com a consequente alteração (aumento) do cérebro, foi fundamental uma nova dieta alimentar. Este período, cerca de 2,5 milhões de anos atrás, também foi marcado por mudanças climáticas que afetaram o comportamento dos hominídeos. Vrba (apud LEONARD; Robertson, 1994, p. 86) afirma que houve uma grande era de resfriamento no planeta naquele período, aumentando, na África, os ambientes áridos e abertos. Ocorreu uma maior abundância de animais nesses novos terrenos, o que implicou, especificamente para o gênero Homo, na maior procura desses animais como sustentos, enquanto o gênero Australopithecus continuou a consumir alimentações mais fibrosas, como vegetais (apesar de comerem carne, eventualmente). Tais atitudes determinariam o consequente aumento do cérebro das espécies do gênero Homo e sua perpetuação.

Diferentes espécies de hominídeos da época parecem ter se adaptado à seca ambiental de diferentes maneiras. Os primeiros membros do gênero Homo (H. habilis e H. erectus) parecem ter incluído maiores quantidades de carne em sua dieta, enquanto os da robusta linhagem australopithecine (por exemplo, A. robustus, A. boisei) continuaram a subsistir em grande parte em alimentos vegetais fibrosos de menor qualidade. Assim, essas mudanças ecologicamente iniciadas no

3 Tradução de: "Adaptation to this calorically dense, easy to digest diet is evident in our gut morphology, as humans have a relatively reduced digestive tract in comparison to most other primates".

4 Tradução de: "Humans represent the positive extreme, having both a very high quality diet and a brain that accounts for $20-25 \%$ of resting metabolic energy". 
comportamento e dieta provavelmente forneceram a base para a seleção sustentada para rápida evolução cerebral nos primeiros membros do gênero Homo. (LEONARD; ROBERTSON, 1994, p. 86 , grifado). ${ }^{5}$

Apesar de outros fatores estarem intrincados para o aumento do cérebro, a dieta envolvendo animais foi fundamental para este acontecimento. Mudanças climáticas forçaram espécies do gênero Homo a se relacionarem com os animais, ou seja, um fator contingencial, mas que permitiu que as espécies evoluíssem até o Homo sapiens.

Pode-se, então, constatar que a relação entre os humanos e os demais animais se iniciou há milhões de anos, por fatores eventuais e de sobrevivência.

Outro momento fundamental nessa relação foi a domesticação dos animais pelos seres humanos. A domesticação levou um tempo gradual e dependeu tanto de intervenções humanas, intencionais ou não, como também da modificação dos ambientes provocados pelos humanos, como afirma especializada doutrina: “[...] domesticação animal ocorreu em escalas de tempo acessíveis através de evidências arqueológicas e foi conduzida por pressões de seleção criadas por ações humanas não intencionais e deliberadas, bem como por ambientes modificados pelo homem". ${ }^{6}$ (LARSON; FULLER, 2014, p. 116).

Uma das hipóteses mais interessantes, proposta por Melinda Zeder (2012), afirma que a domesticação ocorreu de três maneiras. A primeira delas é denominada "caminho comensal" (Commensal Pathway). Inicialmente, não existiu uma intenção humana de atrair animais selvagens para suas localidades. Quando os humanos começaram a adequar o ambiente para si, os animais foram atraídos por sua presença, beneficiando-se dessa relação, ao se alimentar, por exemplo, de restos de comida:

\footnotetext{
5 Tradução de: "Different hominid species of that time appear to have adapted to the environmental drying in different ways. Early members of the genus Homo (H. habilis and H. erectus) appear to have included larger amounts of meat in their diet, while those of the robust australopithecine 'lineage (e.g., A. robustus, A. boisei) continued to subsist largely on fibrous lower quality plant foods. Thus, these ecologically initiated changes in foraging behavior and diet likely provided the basis for sustaining selection for rapid brain evolution in early members of the genus Homo."

6 Tradução de: "[ ] animal domestication has taken place over timescales accessible through archaeological evidence and been driven by selection pressures created by both unintentional and deliberate human actions as well as by human-modified environments".
} 
Este caminho é percorrido por animais que se alimentam de lixo em torno de habitats humanos, ou por animais que atacam outros animais atraídos para ambientes antropogênicos. Esses animais iniciam sua jornada para a domesticação estabelecendo uma relação comensal com os humanos - uma relação na qual um parceiro se beneficia e o outro colhe pouco ou nenhum benefício ou dano. Em algum momento nessa associação com humanos e ambientes antropogênicos, esses animais desenvolvem laços sociais ou econômicos mais próximos com seus hospedeiros humanos, que começam a obter algum benefício tangível da associação. Essa nova reciprocidade coloca o antigo comensal e seu hospedeiro humano em um caminho para um relacionamento doméstico. ${ }^{7}$ (ZEDER, 2012, p. 171)

Animais menos agressivos, como determinadas espécies de lobos selvagens, que viriam a se tornar cães domésticos, são exemplos de animais que se aproximaram dos homens pela via comensal, e que, supõe-se, começou a ocorrer entre 15000 e 14000 anos atrás: "A colocação de cães jovens em enterros humanos em um local no sul do Levante sugere, além disso, que um vínculo social especial havia sido formado entre humanos e cães. (Davis and Valla 1978; Tchernov and Valla 1997; Morey 2005)"” (ZEDER, 2012, p. 172).

A segunda via, denominada "caminho presa" (Prey Pathway), ocorreu quando os humanos passaram a domesticar principalmente gados. Tais animais já eram presas dos homens, que os utilizavam para alimentação. Com o passar do tempo, os humanos passaram a selecionar espécies que melhor se adequavam a este manejo.

A domesticação dessas espécies de presas provavelmente foi iniciada quando, talvez como resposta à pressão localizada sobre o suprimento do animal, os seres humanos começaram a experimentar estratégias de caça projetadas para aumentar a disponibilidade de presas. Com o passar do tempo e com espécies responsivas, [...] essas estratégias se desenvolveram em estratégias de manejo de rebanhos que inclúam o controle multigeracional sustentado sobre o movimento, alimentação e 7 Tradução de: "This pathway is traveled by animals that feed on refuse around human habitats, or by animals that prey on other animals drawn to anthropogenic environments. These animals begin their journey into domestication by establishing a commensal relationship with humans - a relationship in which one partner benefi ts and the other reaps little if any benefit or harm. At some point in this association with humans and anthropogenic environments, these animals develop closer social or economic bonds with their human hosts, who begin to derive some tangible benefit from the association. This new reciprocity sets the former commensal and its human host on a pathway to a domestic relationship".

8 Tradução de: "The placement of young dogs in human burials at one site in the southern Levant suggests, moreover, that a special social bond had been formed between human and dog. (Davis and Valla 1978; Tchernov and Valla 1997; Morey 2005)" 
reprodução dos animais, características da relação doméstica. ${ }^{9}(Z E D E R, 2012$, p. 173-174).

Ovelhas, cabras, porcos e bois são exemplos de espécies que foram domesticadas dessa maneira, a partir do século XII a.C. Estudos genéticos e arqueológicos têm contribuído para se buscar as origens dessa domesticação. (ZEDER, 2012, 174-176).

Um terceiro tipo de domesticação é denominado caminho direcionado (Directed Pathway), que se caracteriza por ser um processo feito pelos humanos de uma maneira mais deliberada e direcionada, a fim de obter recursos com a domesticação de animais que, a princípio, estavam afastados da relação com humanos. Tal estágio, provavelmente, surgiu após a consolidação das vias anteriores. Pode-se ainda afirmar que características que se encontram em determinados animais domesticados, possivelmente, não existiam antes.

\begin{abstract}
Os animais domesticados através desse processo dirigido por intenção, provavelmente não possuem muitas das principais características comportamentais que pré-adaptam certas espécies à domesticação. Como resultado, a domesticação desses animais requer um esforço mais deliberado por parte dos humanos para trabalhar com (ou em torno de) comportamentos inicialmente incompatíveis com a domesticação, com a crescente assistência tecnológica necessária para muitas das espécies domesticadas dessa maneira. ${ }^{10}$ (ZEDER, 2012, p. 176).
\end{abstract}

Cavalos e camelos, por exemplo, foram domesticados dessa forma e já estão, há muito, domados pelos humanos. Entretanto, elefantes, guepardos e falcões, por exemplo, usados na caça ou em outros trabalhos, não são mantidos em cativeiros devido a dificuldades em mantê-los. Entretanto, quando capturados jovens, acabam sendo manejados.

\footnotetext{
9 Tradução de: "Domestication of these prey species was likely initiated when, perhaps as a response to localized pressure on the supply of the animal, humans began to experiment with hunting strategies designed to increase prey availability. Over time and with responsive species [...], these game-management strategies developed into herd-management strategies that included the sustained multigenerational control over the animals' movement, feeding, and reproduction characteristic of the domestic relationship".

10 Tradução de: "Animals domesticated through this intention-driven, directed process are likely not to possess many (or possibly even any) of the key behavioral characteristics that pre-adapt certain species to domestication. As a result, the domestication of these animals requires more deliberate effort on the part of humans to work with (or around) behaviors antithetical to domestication, with increasing technological assistance needed for many of the species domesticated in this way".
} 
De certa forma, esses animais se qualificam como domesticados por estarem engajados em um relacionamento sustentável e multigeracional com os humanos, no qual os humanos assumem um controle considerável sobre seus movimentos, alimentação e proteção para extrair recursos específicos. E, no entanto, uma vez que não são criados em cativeiro, o conjunto normal de fatores seletivos responsáveis pela criação de genótipos domésticos em outros animais domesticados nunca entra em ação. Em vez de passar os traços de domesticação selecionados para cada nova geração, o processo de domesticação começa de novo com cada animal domado para esses propósitos. ${ }^{11}$ (ZEDER, 2012, p. 177).

De certa maneira, as domesticações recentes encontram-se no caminho direcionado, já que nos últimos 200 anos vários animais selvagens são mantidos em cativeiro, com o intuito de fornecer carne, pele e iguarias, como raposas e cervos, por exemplo, e peixes. (ZEDER, 2012, p. 177-178).

A domesticação de animais vem ocorrendo nos últimos 17000 anos, e dependeu de diferentes fatores (culturais, climáticos, geográficos e evolutivos). Juntamente com o início do consumo de derivados dos animais, que tem uma longeva história (2,5 milhões de anos, em média), devese notar que a relação seres humanos e animais é anterior a qualquer visão filosófica, política, econômica e ideológica. Tais fatores devem ser levados em consideração para uma melhor compreensão dessa relação, o que não significa uma compreensão de que os seres humanos estão fadados a um determinismo biológico e comportamental. Somos resultados de processos evolucionários, mas não somente. Por isso, deve-se contextualizar a reflexão filosófica no debate sobre ser humano - animal, o que será feito doravante.

\subsection{Análise filosófica}

Há uma acusação comum e banal de que a maneira como os seres humanos se portam ante os demais animais está pautada numa concepção prévia filosófica. A análise das origens da história dessa relação demonstra que tal afirmação é problemática, pois tem origem na própria pré-história.

11 Tradução de: "In some ways these animals qualify as domesticates in that they are engaged in a sustained, multigenerational relationship with humans, in which humans assume considerable control over their movement, feeding, and protection to extract specific resources. And yet since they are not bred in captivity, the normal array of selective factors responsible for creating domestic genotypes in other animal domesticates never come into play. Instead of passing on selected domestication traits to each new generation, the process of domestication begins anew with each animal tamed for these purposes." 
Entretanto, não se pode abdicar da noção de que a maneira como os seres humanos lidam com os animais possa ser contribuída por uma concepção sobre o mundo. Apesar de toda boa vontade daqueles que procuram afirmar a necessidade de uma passagem de uma suposta visão de mundo antropocêntrica para uma visão biocêntrica ou ecocêntrica, por exemplo, incorre num equívoco que passa despercebido. Pode-se considerar o antropocentrismo, grosso modo compreendido, como a noção de que o homem está no centro da natureza, uma visão arbitrária. Da mesma maneira, quando se afirma o biocentrismo, que tentaria igualar todas as formas de vida, ou o ecocentrismo, a percepção de que todos os entes têm o mesmo valor, como posições a serem seguidas, a fim de mudar a relação com os animais, também se incide em posições arbitrárias. O termo arbitrário neste contexto significa partir de pressupostos sem uma reflexão incisiva.

A questão que se põe é que a defesa de tais noções também pode ser modificada a qualquer momento e por qualquer interesse, por serem visões eventuais. Assim, o ponto que se segue é a crítica a tais posições arbitrárias para, assim, voltar a refletir a relação seres humanos e demais animais.

Apesar do processo biológico ter sido determinante para que houvesse ser humano, ele não pode ser reduzido a ele. O ponto é que a própria afirmação de que o indivíduo é determinado geneticamante/biologicamente já leva em consideração uma pré-compreensão de mundo do homem.

Em Ser e Tempo (1927), Heidegger (1889-1976), ao buscar a resposta pela pergunta pelo Ser, volta-se para o ente capaz de formular essa questão: Dasein (ser-aí), ou seja, o homem enquanto pergunta pelo Ser. A obra é uma análise sobre o Dasein. Para Heidegger o Dasein é existência, isto é, o "próprio ser com a qual a pre-sença ${ }^{12}$ pode se comportar dessa ou daquela maneira e com a qual ela sempre se comporta de alguma maneira. [...] A questão da existência sempre só poderá ser esclarecida pelo próprio existir." (HEIDEGGER, 2005, p. 39). O Dasein não é determinado por uma essência, no sentido de ser um ente definitivo e acabado. "A 'essência' da pre-sença está em sua existência.” (HEIDEGGER, 2005, p. 77). Por isso, é um problema definir o homem arbitrariamente como "animal racional", "imagem de deus", "res cogitans" ou "consciência", por exemplo, pois tais definições são tomadas como evidentes (HEIDEGGER, 2005, p. 85-87), mas, que, na verdade, já carregam em si uma concepção (metafísica) sobre

12 Pre-sença é o termo utilizado pela tradutora desta versão em Português da obra Ser e Tempo para designar Dasein. 
a realidade. Falando da etnologia, e implicitamente sobre as demais ciências, Heidegger afirma que ela está inserida em "determinadas concepções prévias e interpretações da pre-sença humana em geral" (HEIDEGGER, 2005, p. 88). Quando a ciência pretende compreender o mundo em geral, ela também já carrega em si uma pré-compreensão sobre a realidade.

Ao falar sobre uma essência do ser humano ou da realidade, o ponto importante a destacar é que tais visões são ancoradas numa posição metafísica prévia, que pode ser tomada como discricionária. Na verdade, como o ser o humano não teria uma essência, no sentido da metafísica tradicional, constata-se a possibilidade de que sua relação com os demais animais pode sempre se aperfeiçoar, sem a necessidade de pressupor quaisquer "ismos", como antropocentrismo, ecocentrismo ou biocentrismo.

$\mathrm{Na}$ carta Sobre o Humanismo (1946), direcionada a seu interlocutor francês Jean Beafret, Heidegger, ao analisar o que seria o humanismo, chama a atenção para esta mesma crítica, por outro viés, a respeito dos "ismos":

Pergunto-me se isso é necessário. Ou será que não se manifesta, ainda, de modo suficiente, a desgraça que expressões desta natureza provocam? Não há dúvida, de há muito já se desconfia dos "-ismos". Mas o mercado da opinião pública exige constantemente novos. E sempre se está disposto a cobrir esta necessidade.” (HEIDEGGER, 1979, p. 150).

Mas Heidegger, ao falar sobre o Humanismo, vai além de uma crítica a respeito dos "ismos" como explicações do senso comum. Na verdade, sua análise toca na questão apresentada aqui de que tais definições se baseiam numa metafísica e pressupõem um fundamento (o que dependem de uma visão a respeito da realidade). Retomando a tradição ocidental, Heidegger afirma que para Marx, o que torna homem um homem é a sociedade, para o cristão é ser "filho de Deus", para os romanos, influenciado pelos helênicos, é possuir virtudes através da paidéia, visão esta que será retomada constantemente pela tradição ocidental. O ponto em comum é que:

Por mais que se distingam estas espécies de humanismo, segundo suas metas e fundamentos, segundo a maneira e os meios de cada realização, segundo a forma de sua doutrina, todas elas coincidem nisto que a humanitas do homo humanus é determinada a partir do ponto de vista de uma interpretação fixa da natureza, da 
história, do mundo, do fundamento do mundo, e isto significa, desde o ponto de vista do ente em sua totalidade.

Todo humanismo funda-se ou numa Metafísica ou ele mesmo se postula como fundamento de tal. Toda determinação da essência do homem que já pressupõe a interpretação do ente, sem a questão da verdade do ser, e o faz sabendo ou não sabendo, é Metafísica (HEIDEGGER, 1979, p. 153, grifos no original).

Para Heidegger, todo o humanismo toma como essência do homem e interpretação metafísica a noção de que ele é animal rationale, pressupondo até o que é vida. E, assim, questiona:

Do mesmo modo com "animal", zõon, já se pro-pôs uma interpretação da "vida" que repousa necessariamente sobre uma interpretação do ente como zoé e phýsis, em meio a qual se manifesta o ser vivo. Além disto e antes de qualquer outra coisa, resta, enfim, perguntar se a essência do homem como tal, originalmente - e com isto decidindo previamente tudo - realmente se funda na dimensão de animalitas. (HEIDEGGER, 1979, p. 154)

Na carta Sobre o Humanismo, Heidegger retoma a definição de Ser e Tempo de que o homem é sua existência (ec-sistência). Em suas palavras: "O estar postado na clareira do ser denomino eu a ec-sistência do homem. Este modo de ser só é próprio do homem". (HEIDEGGER, 1979, p. 154). Heidegger distingue o homem dos demais entes sem retornar a qualquer tipo de antropocentrismo. Tal característica do homem faz com que volte a criticar a clássica noção de que o homem é um animal racional:

Tais considerações jogam uma estranha luz sobre a determinação corrente e por isso sempre provisória e apressada, do homem como animal rationale. Porque as plantas e os animais estão mergulhados, cada qual no seio de seu ambiente próprio, mas nunca estão inseridos livremente na clareira do ser - e só assim é "mundo" - por isso, falta-lhes a linguagem. E não porque lhes falta a linguagem, estão eles suspensos sem mundo em seu ambiente. [...] Linguagem é advento iluminador-velador do próprio ser. (HEIDEGGER, 1979, p. 155-156).

O ser humano se distingue dos demais entes por existir, ter linguagem e possuir um mundo. O homem existe enquanto questiona o ser, através da linguagem. Já em Ser e Tempo, Heidegger (2005, p. 90) definira 
o Dasein como ser-no-mundo. Os demais entes tornam-se entes propriamente ditos no mundo: "Esses outros entes só podem deparar-se 'com' a pre-sença na medida em que conseguem mostrar-se, por si mesmos, dentro de um mundo." (HEIDEGGER, 2005, p. 96). Em suma, só há um mundo por causa do Dasein, que dá um significado aos demais entes e os relaciona dentro do mundo. Mundo, então, é o domínio das manifestações das relações referenciais. Mundo é uma formação do Dasein.

Na obra "Os conceitos fundamentais da metafísica" (1929), Heidegger volta ao tema do mundo presente em Ser e Tempo, com desdobramentos que, de certa maneira, já foram ilustrados na análise sobre a carta Sobre o Humanismo. O filósofo parte da tese comparativa de que: "1. a pedra (o material) é sem mundo; 2. o animal é pobre de mundo; 3 . o homem é formador de mundo." (HEIDEGGER, 2011, p. 230, grifos no original).

Heidegger inicia sua análise a partir da segunda afirmação: o animal é pobre de mundo. Em comparação com o homem, o animal está preso à circunstância. Cada animal está limitado em suas relações a determinados entes, assim como também está restrito quanto à acessibilidade aos entes, entretanto, "o discurso da pobreza de mundo e da formação de mundo não deve ser tomado no sentido de uma ordem de valores depreciativa." (HEIDEGGER, 2011, p. 251). Heidegger esclarece que "o animal tem seu mundo ambiente (meio ambiente) e movimenta-se nele. Durante sua vida, o animal está encerrado em seu mundo ambiente (meio ambiente) como em um tubo que não se amplia nem se estreita." (HEIDEGGER, 2011, p. 256).

Por sua vez, os objetos materiais, representados por Heidegger pela pedra, não podem ser privados de mundo, pois não os possuem, daí a tese "a pedra não tem mundo", que diferirá os entes materiais dos animais. A pedra não tem qualquer elo com outro ente. Ela está sob o solo, por exemplo, mas não tem qualquer relação com ele, pois:

não tem absolutamente nenhum acesso a algo diverso enquanto tal, ela também não pode absolutamente ser privada de. A pedra é. Ou seja: ela é isto ou aquilo, e é enquanto tal aqui ou lá. Ela está ou não está simplesmente dada. Ela é - mas ao seu ser pertence a essencial ausência de acesso, sob o domínio da qual ela é à sua maneira (ser simplesmente dado. A pedra é sem mundo. A ausência de mundo de um ente em questão e que justamente caracteriza sempre a cada vez este modo de ser. (HEIDEGGER, 2011, p. 254). 
Por fim, Heidegger se debruça sobre a afirmação de que "o homem é formador de mundo". Para falar do mundo deve-se falar daquilo que está manifesto, dos entes que estão diante do homem em sua cotidianidade, ou seja, da relação do homem com os demais entes. (HEIDEGGER, 2011, p. 352-354). Heidegger enfatiza a relação intrínseca entre homem e mundo, afirmando que mundo "é a abertura do ente enquanto tal na totalidade." (HEIDEGGER, 2011, p. 365, grifos no original).

$\mathrm{O}$ ente do qual Heidegger fala na frase anterior é o homem, e a totalidade corresponde à soma das manifestações dos entes para o homem. "Enquanto tal", por sua vez, revela algo como "a enquanto b", que é mesmo que a proposição "a é b": "Segundo esta estrutura, portanto, o 'enquanto' faz parte da simples proposição enunciativa. O 'enquanto' é um momento estrutural da estrutura da proposição no sentido da simples proposição enunciativa." (HEIDEGGER, 2011, p. 369, grifos no original). A proposição enunciativa é fundamental para a construção do mundo.

Ademais, ao falar sobre o "enquanto", como "a é b" necessariamente está a se falar do "é", do ser. Heidegger critica a noção do ser tomado como ente (o que, em sua visão, fez toda a metafísica ocidental), assim, propõe a diferença entre ser e os entes, a diferença ontológica ${ }^{13}$. Ao tratar dessa diferença, "compreendemos o problema do mundo (HEIDEGGER, 2011 , p. 457, grifos no original). O que irá permitir essa diferença (ser e entes) é o que Heidegger (2011, p. 463) denomina estrutura originária do acontecimento fundamental, e isto é o projeto: "O projeto enquanto estrutura originária do acontecimento citado é a estrutura originária da formação de mundo [...] projeto é projeto de mundo. O mundo vigora em e para um deixar viger que possui o caráter do projetar." (HIEDEGGER, 2011, p. 465, grifos no original). Mais uma vez Heidegger enfatiza a relação homem e mundo, por isso, quando fala em projeto do homem, isso se reflete no projeto do mundo.

A consequência desta análise é de que mundo existe com o homem, mas não enquanto algo definitivo. O Dasein tem inúmeras possibilidades no mundo, que é projetado num contexto referencial de significação. Assim, por mais que o ser humano se encontre num mundo já constituído, por não haver uma essência definitiva, ele pode projetar novas formas de lidar com os animais, sem voltar à metafísica. E, com certeza, o Direito participa deste projeto.

13 Já colocada em Ser e Tempo §2. 


\section{O RETORNO DA BIOÉTICA A SEUS MÚLTIPLOS REFEREN- CIAIS DE CONSIDERAÇÃO.}

Doravante, far-se-á breve excurso na Ética Animal sem recorrer mais profundamente à senciência. A opção por afastar, nesse texto, a senciência se dá por três motivos principais: $1^{\circ}$ ) Essa já é a fundamentação mais comum e aceita nos meios de debates sobre animais. $2^{\circ}$ ) A senciência é algo verificável cientificamente, embora possamos fazer ressalvas acerca de diferentes graus de senciência. Podemos até mesmo nos referir à consciência de alguns animais. $3^{\circ}$ ) A senciência conduz a uma proteção restritiva, isto é, dos animais que comprovadamente sentem dor, mas não dos animais que têm sistema nervoso radial, ganglionar ou reticular, cuja formação comparativamente mais simples não permite tal verificação.

Por isso, os argumentos serão erigidos em um fundamento que se pretende mais amplo: a própria Bioética. Mas não a Bioética médica, também restritiva, mas à Bioética que trabalha com múltiplos referenciais de consideração e, assim, não se restringe aos animais que reconhecidamente apresentam alto grau de senciência.

Aqueles que estudam a Bioética já devem conhecer, mas é sempre bom lembrar que o vocábulo Bioética foi trabalhado pela primeira vez, em 1927, pelo filósofo alemão Fritz Jahr, em seu artigo "Bioética: um panorama da ética e as relações do ser humano com os animais e plantas".

Jahr (1927) propôs um imperativo bioético de respeito a todas as formas de vida, como um fim em si mesmas. A Bioética seria uma disciplina acadêmica, um princípio e uma virtude, que, como tal, imporia obrigações morais em relação a todos os seres vivos.

Dessa forma, alargar-se-ia o referencial de Ética vigente à sua época para alcançar todos os seres vivos. Esta Ética ampla seria a Bioética. Ele se utiliza das considerações de Francisco de Assis e de Schopenhauer e diz ser irrefutável a necessidade de estender a Ética aos animais. (JAHR, 1927)

A expressão Bioética popularizou-se, no entanto, a partir da obra "Bioética: ponte para o futuro", de 1971, do oncologista estadunidense Van Rensselaer Potter. O nome do livro é sugestivo: Potter (2016) propunha a construção de uma Ética ponte, capaz de mediar as relações entre as Ciências e as Humanidades, voltada para os problemas ambientais e para as questões de saúde.

Nascida como Ética da Vida, com preocupações ambien- 
tais e de saúde humana, a Bioética, especialmente nas décadas de 1970 e 1980, afastou-se de sua matriz ecológica e reforçou suas preocupações com o avanço das Ciências Médicas.

Essa mudança de foco deveu-se a discussões de dilemas médicos na Universidade de Georgetown (EUA), sobretudo sob a liderança de André Hellegers. A ideia central era permitir que tais dilemas fossem debatidos não apenas por médicos, mas também por filósofos e teólogos. (NAVES; REIS, 2016)

No entanto, a visão era restritiva: questões sobre meio ambiente ou outros seres vivos não eram considerados como problemas bioéticos.

Essa posição restritiva ainda foi fortalecida pela criação, em 1974, também nos Estados Unidos, da Comissão Nacional para a Proteção dos Interesses Humanos de Biomedicina e Pesquisa Comportamental. Essa Comissão, quatro anos mais tarde, apresentou o Relatório Belmont, com os princípios éticos básicos que norteiam a experimentação com seres humanos: respeito pelas pessoas, beneficência e justiça. (NAVES; REIS, 2016)

Ao que parece, o homem ainda não havia se dado conta de que é impossível discutir temas de saúde sem discutir questões sobre meio ambiente e também de que é impossível, contemporaneamente, trabalhar ética sem levá-la à consideração de outros seres vivos.

Nas últimas décadas, no entanto, temos vivido um movimento que tenta valorizar, na Bioética, as discussões mais amplas, ainda que sua atuação nem sempre tenha se dado de forma rigorosa.

A afirmação de que algumas pesquisas sobre a Bioética ampliada nem sempre são rigorosas pauta-se, principalmente, na falha do marco filosófico para justificar valores intrínsecos aos outros seres vivos, inclusive a dignidade animal.

De forma nenhuma desconsideramos os esforços de pesquisadores que procuram encontrar fundamento ético para suas teses sobre a proteção aos animais. No entanto, metodologicamente, muitas dessas tentativas apresentam falhas por escolherem como marco fundante filósofos que não tiveram os animais por consideração ou mesmo uma ética que ultrapassasse a reciprocidade.

Por exemplo, no caso dos profissionais do Direito que pretendem justificar a dignidade dos animais, ainda é comum a utilização da Ética kantiana.

Ora, Kant é um marco filosófico para o desenvolvimento da Ética, mas sua teoria foca-se no ser humano como agente e referencial moral. 
O imperativo categórico de Kant coloca a vontade humana, e consequentemente a liberdade, no centro da Ética da Primeira Modernidade. O agir ético dependeria sempre da possibilidade do agente avaliar sua conduta racionalmente. A liberdade suprema da vontade seria estar vinculado ao dever, ao dever imposto pela própria razão. (KANT, 1997)

A leitura que se pode fazer dessa Ética é que a ausência de racionalidade na vida extra-humana impediria que a Ética alcançasse outros seres vivos, já que estes não possuiriam um agir moral.

Assim, a Ética, com Kant, assumiu como condição a alteridade racional ou da reciprocidade, restringindo-se ao ser humano como sujeito e destinatário de sua ação. Até hoje, fundamentados em Kant, autores sustentam que a Ética não se aplica aos animais porque eles não são sujeitos que possam ter deveres morais.

Por isso, utilizar Kant para fundamentar uma Ética para os seres vivos ou a dignidade dos animais mostra-se metodologicamente equivocado. Não basta uma releitura de Kant, porque seus pressupostos antrópicos exigiriam recorrer à construção de um arcabouço completamente diferente de argumentos e princípios.

Portanto, o esforço transformador deve ser bem maior. Foi o caso do trabalho empreendido por Hans Jonas (1903-1993), que sugere um novo imperativo categórico, que se estenderá em direção ao futuro. Vale a pena ler um pequeno trecho de sua proposta:

O Imperativo categórico de Kant dizia: ‘Aja de modo que tu também possas querer que tua máxima se torne lei geral' [...] para um imperativo mais condizente ao novo tipo do agir humano: 'Aja de modo a que os efeitos de tua ação sejam compatíveis com a permanência de uma autêntica vida humana sobre a Terra' [...]." (JONAS, 2006, p. 47)

Com a reformulação, o imperativo kantiano tendente à individualidade e ao privado assume um outro aspecto, que se propaga para o público, para a sociedade presente e futura, inclusive para os demais seres e ecossistemas.

Jonas (2006) também afirma a extinção da ideia tradicional de direitos e deveres éticos, pelo qual o meu dever é a imagem refletida do dever alheio. Com o pressuposto da reciprocidade ou da alteridade racional, o individualismo humano é posto de lado para se erguer uma nova proposta de Ética. 
A projeção da ética de Jonas para o futuro conduz até mesmo a um "sujeito" que não existe, não reivindica e não tem seus direitos lesados: as futuras gerações. E mais, dirige-se também a outras formas de vida, já que a ética passa a ser uma parte da filosofia da natureza. (JONAS, 2006) A nova Ética preocupa-se com o ser e não somente com o ser humano:

[...] só uma ética fundamentada na amplitude do ser, e não apenas na singularidade ou na peculiaridade do ser humano, é que pode ser de importância no universo das coisas. Ela terá esta importância se o ser humano a tiver; e se ele a tem, nós teremos que aprendê-lo a partir de uma interpretação da realidade como um todo, ou pelo menos a partir de uma interpretação da vida como um todo. [...] Portanto, enquanto a investigação ontológica extra-humana puder levar-nos para a teoria universal do ser e da vida, ela não se terá afastado realmente da ética, mas terá ido atrás de sua fundamentação possível. (JONAS, 2004, p. 272)

Assim, é plenamente viável que os animais, não só os com alto grau de senciência, mas todos eles, inclusive os demais seres vivos, recebam consideração moral da nova Bioética. Uma Bioética que tenha múltiplos referenciais de consideração e que pense para o futuro do planeta.

E é dessa Bioética que deve influenciar a base do Direito. Alguns, mais pessimistas com a situação atual, podem até dizer que isso é muito difícil, pois o hodierno Direito é antropocêntrico!

A verdade é que o Direito não é antropocêntrico nem biocêntrico ou ecocêntrico. Os valores sociais até podem ser classificados em antropocêntricos ou biocêntricos, mas o Direito, a lei não é nenhum deles. Porque a lei não é valor, mas contém valor. Mas não valores fixos, até porque a lei não é nada sem a interpretação.

Além disso, essa classificação dos valores, normalmente colocados dicotomicamente entre biocêntricos e antropocêntricos, tem pouca relevância prática se não se pautarem em um sistema ético coerente.

O Direito é, sobretudo, um discurso, uma argumentação sobre uma certa semântica da lei. Não há um sentido pronto para a lei. Todo sentido é construído e localizado historicamente. E, por isso mesmo, influenciado pelos valores. É importante ler tais valores à luz de uma Bioética ampla.

A compreensão é histórica e só pode se realizar na história. O que significa que a história conduz e limita toda atribuição de sentido. 
O Direito é importante, mas ainda mais importante e definitivo é a criação de arcabouço ético que fundamente e legitime as decisões sociais.

É preciso a Bioética, construída a partir dos novos paradigmas filosóficos propostos neste e no capítulo anterior, para compor o horizonte que limita a interpretação do Direito que se quer aplicável aos animais.

\section{POLÍTICA DE SAÚdE ÚNICA E A TUTELA PENAL DA VIDA ANIMAL}

O mergulho ético filosófico da relação homem-animal e a nova Ética proposta por Jonas em superação ao imperativo categórico Kantiano em prol de uma nova postura perante os demais animais, deve render frutos que espelhem políticas públicas de saúde animal e transformem, em favor da existência e sobrevivência de presentes e futuras gerações de seres, práticas legislativas adequadas no âmbito do direito penal, em especial, no tocante à tutela da vida.

Quanto à primeira, ou seja, quanto à questão da saúde única, fator de grande impacto no reconhecimento e efetivação do bom trato aos animais, não se trata de questão nova, posto que reconhecida pela Organização Mundial da Saúde (WHO, online) e, dada a aproximação de origem entre homem e animal e a comum convivência mundana, pelo próprio Conselho Federal de Medicina Veterinária, que assim expôs a questão em seu sítio eletrônico:

A Saúde Única representa uma visão integrada da saúde, considerada única e composta por três áreas indissociáveis: humana, animal e ambiental. A interligação das três áreas da saúde é reconhecida por organizações internacionais como a Organização Mundial da Saúde Animal (OIE) e a Organização Mundial da Saúde (OMS). O conceito propõe a atuação conjunta da Medicina Veterinária, da Medicina humana e de outros profissionais da saúde. Esta integração pode contribuir para o desenvolvimento de pesquisas, aumentar o conhecimento científico disponível e melhorar a educação médica e o cuidado clínico. Como resultado, aumenta-se a eficácia das ações em saúde pública com redução dos riscos para a saúde global. As interações ecológicas entre humanos e animais acontecem em diversos ambientes e de diferentes maneiras. Essas interações podem ser responsáveis pela transmissão de doenças entre homens e animais, as conhecidas zoonoses. Segundo a Organização 
Mundial da Saúde Animal (OIE), cerca de 60\% das doenças humanas são zoonóticas. (BRASIL, CFMV, 2018, online)

Vê-se, pois, que políticas de saúde única viriam atender anseios dos homens, dos animais e do meio ambiente em geral, em conservação dos seres habitantes do globo. Todavia, não obstante a diretriz de política pública voltada para a compreensão e efetivação da saúde única e, por conseguinte, da saúde animal, a realidade brasileira e de alguns países tem sido muito diferente - na contramão do apregoado por Jonas (2004) e pela nova Bioética, que transcende a individualidade humana e preocupa-se com os seres em geral - e está atada aos interesses do homem, a quem são dedicados os maiores esforços, principalmente em âmbito orçamentário:

[...] De acordo com a legislação pertinente ao SUS e com a Lei Complementar 141, de 13 de janeiro de 2012, os recursos do setor público de saúde no Brasil não podem ser aplicados em outras políticas públicas. Assim, cabe a cada esfera de governo - responsável pela aplicação dos recursos destinados às ações e serviços públicos de saúde voltados para vigilância, prevenção e controle de zoonoses e de acidentes causados por animais peçonhentos e venenosos, de relevância para a saúde pública - avaliar criteriosamente as políticas públicas de saúde e diferenciá-las das políticas públicas de meio ambiente, saúde animal, bem estar animal, limpeza e segurança pública e viária ou quaisquer outras relacionadas à execução de ações sobre as populações de animais [...] (BRASIL, 2014, online).

Nota-se, portanto, que, ao arrepio da noção de saúde pública orientada pela nova Bioética aproximativa da relação homem-animal, o Poder Público não poderia negligenciar o cuidado com os animais (dever constitucional imposto no art. $225, \S 1^{\circ}$, VII) e a elaboração de políticas públicas que os contemplassem (em sintonia com a ideia de saúde única). Afinal, como forma de cumprimento de políticas de saúde única, os animais, ainda que por rubrica orçamentária destinada ao homem, deveriam, em nome de uma política unitária, receber uma maior e melhor atenção do Estado quanto aos serviços veterinários por ele oferecidos.

Todavia, o desrespeito aos animais não para por aí. Isso porque ao arrepio do arcabouço ético que deve nortear a questão do trato animal e, por conseguinte, políticas criminais de tutela animal, tampouco o direito penal, sabidamente fragmentário e subsidiário, mas que contempla, por sua importância, alguns tipos penais de proteção da fauna, tem dado resposta 
adequada a condutas ofensivas à vida animal, principalmente do animal doméstico.

Cumpre dizer que a fauna possui papel fundamental no equilíbrio dos ecossistemas e na diversidade biológica. Aliás, todos os organismos possuem estreita relação entre si e com os demais componentes do meio, sejam eles vivos ou não, garantindo a preservação das espécies. De acordo com Milaré (2011), a fauna, interagindo ou não com esses outros elementos,

[...] funciona como um dos termômetros da biodiversidade na manutenção do equilíbrio ecológico. Por isso mesmo, ela é um dos grandes indicadores das ameaças que pairam sobre o conjunto da vida no Planeta, haja vista o que ocorre no extermínio de espécies. Ela não é somente indicador valioso, também é um sinal de alerta (MILARÉ, 2011, p. 300).

Em razão dessa importância, a Constituição Federal de 1988 estabeleceu deveres específicos ao Poder Público (e à própria coletividade), consistentes, na forma do artigo $225, \S 1^{\circ}$, VII, na proteção da fauna e de práticas que coloquem em risco sua função ecológica, provoquem a extinção de espécies ou submetam os animais à crueldade.

O conceito de fauna, assim como o de meio ambiente, coube especialmente aos doutrinadores, que o extraíram da biologia e de outras matérias transdisciplinares ao direito ambiental. Fiorillo (2014, p. 311), por exemplo, entende a fauna como o coletivo de animais de uma dada região ou período geológico. $\mathrm{O}$ autor ainda destaca a subdivisão em: a) fauna silvestre, por ele compreendida conjunto de animais que vivem em liberdade, fora do cativeiro, cujo conteúdo já havia sido abarcado pelo artigo $1^{\circ}$ da também recepcionada Lei n. 5.197/67 e, b) doméstica, compreendida pelos animais que não vivem em liberdade, e sim em cativeiro, e convivem geralmente em harmonia com a presença humana, inclusive com vínculo de dependência para sobreviver.

A previsão constitucional ${ }^{14}$ irradiou a tutela para legislações infraconstitucionais e demais microssistemas jurídicos.

A título de conhecimento, destacam-se: Lei n. 5.197/67, supramencionada, específica sobre a fauna silvestre; Lei n. 7.643/87, que proíbe a pesca de cetáceos $^{15}$ nas águas brasileiras; Lei n. 10.519/02, regulamenta-

14 No âmbito internacional, o Brasil é um dos países signatários da Declaração Universal dos Direitos dos Animais, proclamada em 27 de janeiro de 1978.

15 Segundo definição do dicionário Houaiss (2010, p. 157), cetáceo faz parte da “ordem de mamíferos 
dora da defesa sanitária animal na realização de rodeios; Lei n. 11.794/08, a qual estabelece os procedimentos para uso científico dos animais; Lei n. 11.959/09, que regulamenta as atividades pesqueiras; Decreto-Lei n. 6.514/08, referente às infrações administrativas ao meio ambiente; Decreto n. 3607/00, alusivo à efetivação da Convenção sobre Comércio Internacional das espécies da flora e fauna selvagens em perigo de extinção.

A proteção constitucional da fauna também permitiu a tipificação penal de determinadas práticas ofensivas ao conjunto de espécies animais, sem olvidar da tratativa cível e administrativa, e isso com base no $\S 3^{\circ}$ do artigo 225, o qual prevê que as "condutas e atividades consideradas lesivas ao meio ambiente sujeitarão os infratores, pessoas físicas ou jurídicas, a sanções penais e administrativas, independentemente da obrigação de reparar os danos causados". (BRASIL, 1988).

Essa responsabilidade penal ambiental foi delimitada na Lei n. 9605/98, que dispõe sobre os crimes ambientais em espécie, entre os quais aqueles prejudiciais à fauna, previstos nos artigos 29 a 37 (BRASIL, 1988).

A pretensão de corresponder ao mandamento protecionista da Constituição no tocante ao bem jurídico meio ambiente ecologicamente equilibrado, porém, não encontrou total sucesso com a Lei de Crimes Ambientais, segundo diversificadas e justificadas críticas (PRADO, 2012, p. 184), alcançando, contudo, o ponto auge das críticas, o teor artigo $32^{16}$. Isso porque tal artigo representou verdadeiro acinte à vida dos animais domésticos (cães, cavalos e gatos, etc.), mormente no tocante à ausência de previsão do verbo matar, prevendo apenas as ações de ferir e mutilar, além dos atos de abuso e maus-tratos. Assim, ao contrário da previsão do artigo $29^{17}$, que prevê a conduta de matar, mas que se limita à tutela dos animais silvestres, os domésticos sequer possuem a vida tutelada no âmbito do ramo menos indulgente do direito, o penal.

À vista dessa ausência de previsão do biocídio no tocante aos animais domésticos já que, como dito, o verbo matar somente encontra

aquáticos", tais como a baleia e o golfinho.

16 Art. 32. "Praticar ato de abuso, maus-tratos, ferir ou mutilar animais silvestres, domésticos ou domesticados, nativos ou exóticos:

Pena - detenção, de três meses a um ano, e multa".

17 Art. 29. "Matar, perseguir, caçar, apanhar, utilizar espécimes da fauna silvestre, nativos ou em rota migratória, sem a devida permissão, licença ou autorização da autoridade competente, ou em desacordo com a obtida:

Pena - detenção de seis meses a um ano, e multa” 
previsão em artigo não dedicado ao animal doméstico, o Brasil, contrariando a nova Ética que apregoa a corresponsabilidade das diversas espécies em prol da manutenção da vida, demonstra, em âmbito legislativo, desprezo à vida animal e, em âmbito normativo, descumprimento à Declaração Universal dos Direitos dos Animais, proclamada pela UNESCO em 27 de janeiro de 1978, e que tem o Brasil como signatário. Referida Declaração, em seu artigo $3^{\circ}$, "a", prevê que "nenhum animal deverá ser submetido a maltrato e a atos cruéis"; no artigo $6^{\circ}$, "b", adverte que "o abandono de um animal é um ato cruel e degradante"; no artigo 10, "a", aduz que "nenhum animal deve ser usado para divertimento do homem"; e no artigo 11 assevera que "o ato que leva à morte de um animal sem necessidade é um biocídio, ou seja, um delito contra a vida" (grifado ante a pertinência ao tema).

Observa-se, assim, que, no tocante ao âmbito jurídico, muito ainda há de ser feito no Brasil, a ponto de se poder dizer, quanto à vida do animal doméstico, que os ditames constitucionais e internacionais seriam suficientes como bases para uma legislação infraconstitucional mais eficaz na tutela do bem jurídico protegido ${ }^{18}$; todavia, a realidade demonstra uma lei repleta de deficiências e que precisa ser reformulada para atender efetivamente os objetivos pretendidos.

\section{CONSIDERAÇÕES FINAIS}

As relações entre os homens e os demais animais, que remontam à origem das espécies, à seleção natural e à própria alimentação no tocante às energias acumuladas para a mutação e desenvolvimento dos seres, demonstram, desde os pontos de vista histórico e biológico, a existência de uma ligação, que de natureza antropocêntrica, biocêntrica ou ecocêntrica os autores em geral procuram adjetivar.

Sob a ótica filosófica, contudo, o texto buscou, em início, revelar que tais concepções antropocêntricas e/ou bicoêntricas/ecocêntricas, se não precedidas de reflexão, serão sempre eventuais e efêmeras, podendo ser modificadas à luz de um interesse qualquer. Busca-se em Heidegger um referencial que propõe a ideia de que o homem, como formador de mundo, por isso, projeto, pode aperfeiçoar sua relação com os demais animais.

Como ponte entre a filosofia e o direito, uma nova Bioética, de

18 Tal como sustentado em "Veredas do Direito", urge a concepção de novas referências para orientar e estruturar o ambiente, e, por conseguinte, a vida animal, "de forma solidária e interdependente, evitando as exclusões e outras formas de dominação e exploração” (AQUINO; ZAMBAM, 2017, p. 103). 
cunho mais solidário e que tem preocupação com a amplitude do ser e não do ser humano em especial, apresenta um novo imperativo categórico que supera Kant em prol de maior e melhor corresponsabilidade das diversas espécies para a manutenção da vida e que tem seu maior expoente em Hans Jonas.

A relação estabelecida no texto entre Heidegger e o novo imperativo categórico da nova Bioética está na superação da metafísica como forma de adjetivar as relações entre homem e animal, o que justifica práticas jurídicas capazes de consagrar políticas de saúde única para homem e animal e a necessidade de aperfeiçoamento legislativo consagrador da solidariedade entre os seres, sendo ao animal, por isso, merecedor de uma tutela plena e efetiva da vida pelo e através do direito.

Apregoa-se um ideal de saúde única já conhecida, mas não adotada no Brasil, e de uma legislação penal aperfeiçoada, tutora da vida de todo e qualquer animal não humano, inclusive o doméstico, que não foi agraciado com tal proteção pelo vigente artigo 32, da Lei 9605/95.

\section{REFERENCIAS}

AQUINO, Sérgio Ricardo Fernandes de; ZAMBAM, Neuro José. A Casa Comum: por uma epistemologia do cuidado e justiça para a América Latina. Veredas do Direito, Belo Horizonte, v. 14, n. 29, p. 101-123, maio/ ago. 2017. Disponível em: <http://www.domhelder.edu.br/revista/index.php/ veredas/article/view/999/615> Acesso em: 26 mar. 2018.

BRASIL, Assembleia Nacional Constituinte. Constituição da República Federativa do Brasil. Brasília: Imprensa Nacional. Diário Oficial da União, 05 de outubro de 1988. Disponível em: <http://www.planalto. gov.br/ccivil03/constituicao/constitui\%C3\%A7ao.htm>. Acesso em: 23 mar. 2018.

BRASIL, Congresso Nacional. Lei n. 9605, de 12 de fevereiro de 1998. Brasília: Imprensa Nacional. Diário oficial da União, 13 de fevereiro de 1998. Disponível em: <http://www.planalto.gov.br/ccivil_03/leis/L9605. htm>. Acesso em: 23 mar. 2018.

BRASIL, Conselho Federal de Medicina Veterinária. O que é saúde única? Disponível em: <http://portal.cfmv.gov.br/uploads/files/folder_SU.pdf $>$ Acesso em: 24 mar. 2018.

BRASIL, Ministério da Saúde. Disponível em: <http://portalsaude.saude. gov.br/index.php/o-ministerio/principal/leia-mais-o-ministerio/197-sec- 
retariasvs/14874-esclarecimento-sobre-a-portaria-n-1-138-gm-ms-de-23de-maio-de-2014>. Acesso em: 17 nov. 2016.

FIORILLO, Celso Antônio Pacheco. Curso de direito ambiental brasileiro. São Paulo: Saraiva, 2014.

HEIDEGGER, Martin. Os conceitos fundamentais da metafísica: mundo, finitude e solidão. $2^{\mathrm{a}}$ ed. Trad. Marcos Antônio Casanova. Rio de Janeiro: Forense Universitária, 2011.

HEIDEGGER, Martin. Ser e Tempo - Parte I. 15a ed. Trad. Márcia Sá Cavalcante Schuback. Petrópolis; Bragança Paulista: Editora Vozes; Universidade São Francisco, 2005.

HEIDEGGER, Martin. Sobre o "Humanismo" - Carta a Jean Beaufret, Paris. Trad. Ernildo Stein. In: Conferências e escritos filosóficos (Col. Os Pensadores - Martin Heidegger). São Paulo: Abril Cultural, 1979, p. 147175.

JAHR, Fritz. "Bioethik: eine Übersicht der Ethik und der Beziehung des Menschen mit Tieren und Pflanzen". Kosmos, Gesellschaft der Naturfreunde, Stuttgart, Nr. 24, p. 21-32, 1927.

JONAS, Hans. O princípio responsabilidade: ensaio de uma ética para a civilização tecnológica. Rio de Janeiro: PUC Rio/Contraponto, 2006.

JONAS, Hans. O princípio vida: fundamentos para uma biologia filosófica. Petrópolis: Vozes, 2004.

KANT, Immanuel. Fundamentação da metafísica dos costumes. Lisboa: Edições 70, 1997.

LARSON, Greger; FULLER, Dorian Q. The Evolution of Animal Domestication. The Annual Review of Ecology, Evolution, and Systematics. V. 45, p. 115-136, 2014. Disponível em: <https://www.annualreviews.org/ doi/pdf/10.1146/annurev-ecolsys-110512-135813>. Acesso em: 20 mar. 2018 .

LEONARD, William R.; ROBERTSON, Marcia L. Evolutionary Perspectives on Human Nutrition: The Influence of Brain and Body Size on Diet and Metabolism. American Journal Of Human Biology, New York, v. 6, ed. 1, p. 77-88, jan. 1994. Disponível em: $<$ https://www.ncbi.nlm. nih.gov/pubmed/28548424>. Acesso em: 17 mar. 2018.

MILARÉ, Édis. Direito do ambiente: doutrina, jurisprudência, glossário. 7. ed. São Paulo: Editora Revista dos Tribunais, 2011. 
NAVES, Bruno Torquato de Oliveira; REIS, Émilien Vilas Boas. Bioética ambiental: premissas para o diálogo entre a Ética, a Bioética, o Biodireito e o Direito Ambiental. Rio de Janeiro: Lumen Juris, 2016.

POTTER, Van Rensselaer. Bioética: ponte para o futuro. São Paulo: Loyola, 2016.

PRADO, Luiz Regis. Direito penal do ambiente. 4. ed. rev., atual. e ampl. São Paulo: Revista dos Tribunais, 2012.

RIBEIRO, Luiz Gustavo Gonçalves; COELHO, Ariadne Elloise. A tutela penal da fauna e a inadequação constitucional do artigo 32 da Lei de Crimes Ambientais. In: VASCONCELOS, Fernando Antônio de; ÁVILA, Gustavo Noronha de; RIBEIRO, Luiz Gustavo Gonçalves ( Org. ). Direito penal, processo penal e Constituição I. Florianópolis: Conpedi, 2017, p. 44-59. Disponível em: <https://www.conpedi.org.br/publicacoes/roj0xn13/9t8274u3> Acesso em: 24 mar. 2018.

RIBEIRO, Luiz Gustavo Gonçalves; MAROTTA, Clarice Gomes. Judicialização de políticas públicas em prol dos animais: uma visão de saúde única. Revista Brasileira de Políticas Públicas, Brasília, v. 7 n. 1, p. 74-87. Disponível em: <https://www.publicacoesacademicas.uniceub.br/RBPP/ article/view/4480.> Acesso em: 22 mar. 2018.

WORLD HEALTH ORGANIZATION. Global elimination of dog-mediated human rabies. Disponível em: <http://www.who.int/neglected_diseases/resources/who_htm_ntd_nzd_2016.02/en/.> Acesso em: 23 mar. 2018.

ZEDER, Melinda A. The domestication of animals. Journal of Anthropological Research, Chicago v. 68, $\mathrm{n}^{\circ} 2$, p. 161-190. Disponível em: $<$ https://www.journals.uchicago.edu/doi/abs/10.3998/jar.0521004.0068.201>. Acesso em: 20 mar. 2018.

Artigo recebido em: 30/03/2087.

Artigo aceito em: 07/05/2018.

\section{Como citar este artigo (ABNT):}

REIS, E. V. B; NAVES, B. T. O.; RIBEIRO, L. G. G. UM POSICIONAMENTO JURÍDICO-FILOSÓFICO CONTRA A METAFÍSICA DOS "ISMOS": UMAANÁLISE SOBRE OS ANIMAIS. Veredas do Direito, Belo Horizonte, v. 15, n. 31, p. 67-94, jan./abr. 2018. Disponível em: $<$ http:// www.domhelder.edu.br/revista/index.php/veredas/article/view/1265>. Acesso em: dia mês. ano. 